\title{
Progressive myocardial injury in myotonic dystrophy type II and facioscapulohumeral muscular dystrophy 1: a cardiovascular magnetic resonance follow-up study
}

Edyta Blaszczyk ${ }^{1,2}$, Carolin Lim ${ }^{1,2}$, Peter Kellman ${ }^{3}$, Luisa Schmacht ${ }^{1}$, Jan Gröschel ${ }^{1,2}$, Simone Spuler ${ }^{4}$ and Jeanette Schulz-Menger ${ }^{1,2^{*}}$ (i)

\begin{abstract}
Aim: Muscular dystrophy (MD) is a progressive disease with predominantly muscular symptoms. Myotonic dystrophy type II (MD2) and facioscapulohumeral muscular dystrophy type 1 (FSHD1) are gaining an increasing awareness, but data on cardiac involvement are conflicting. The aim of this study was to determine a progression of cardiac remodeling in both entities by applying cardiovascular magnetic resonance (CMR) and evaluate its potential relation to arrhythmias as well as to conduction abnormalities.

Methods and results: 83 MD2 and FSHD1 patients were followed. The participation was $87 \%$ in MD2 and 80\% in FSHD1. 1.5 T CMR was performed to assess functional parameters as well as myocardial tissue characterization applying $\mathrm{T} 1$ and $\mathrm{T} 2$ mapping, fat/water-separated imaging and late gadolinium enhancement. Focal fibrosis was detected in 23\% of MD2) and 33\% of FSHD1 subjects and fat infiltration in 32\% of MD2 and 28\% of FSHD1 subjects, respectively. The incidence of all focal findings was higher at follow-up. T2 decreased, whereas native T1 remained stable. Global extracellular volume fraction (ECV) decreased similarly to the fibrosis volume while the total cell volume remained unchanged. All patients with focal fibrosis showed a significant increase in left ventricular (LV) and right ventricular (RV) volumes. An increase of arrhythmic events was observed. All patients with ventricular arrhythmias had focal myocardial changes and an increased volume of both ventricles (LV end-diastolic volume (EDV) $p=0.003$, RVEDV $p=0.031)$. Patients with supraventricular tachycardias had a significantly higher left atrial volume $(p=0.047)$.

Conclusion: We observed a remarkably fast and progressive decline of cardiac morphology and function as well as a progression of rhythm disturbances, even in asymptomatic patients with a potential association between an increase in arrhythmias and progression of myocardial tissue damage, such as focal fibrosis and fat infiltration, exists. These results suggest that MD2 and FSHD1 patients should be carefully followed-up to identify early development of remodeling and potential risks for the development of further cardiac events even in the absence of symptoms.
\end{abstract}

\footnotetext{
*Correspondence: jeanette.schulz-menger@charite.de

${ }^{1}$ Department of Cardiology and Nephrology, Working Group Onn Cardiovascular Magnetic Resonance, Experimental and Clinical Research

Center a Joint Cooperation Between the Charité - Universitätsmedizin Berlin, Department of Internal Medicine and Cardiology and the MaxDelbrueck Center for Molecular Medicine, and HELIOS Klinikum Berlin Buch, Lindenberger Weg 80, 13125 Berlin, Germany

Full list of author information is available at the end of the article
} permits use, sharing, adaptation, distribution and reproduction in any medium or format, as long as you give appropriate credit to the original author(s) and the source, provide a link to the Creative Commons licence, and indicate if changes were made. The images or other third party material in this article are included in the article's Creative Commons licence, unless indicated otherwise in a credit line to the material. If material is not included in the article's Creative Commons licence and your intended use is not permitted by statutory regulation or exceeds the permitted use, you will need to obtain permission directly from the copyright holder. To view a copy of this licence, visit http://creativecommons.org/licenses/by/4.0/. The Creative Commons Public Domain Dedication waiver (http://creativeco mmons.org/publicdomain/zero/1.0/) applies to the data made available in this article, unless otherwise stated in a credit line to the data. 
Trial registration ISRCTN, ID ISRCTN16491505. Registered 29 November 2017 - Retrospectively registered, http://www. isrctn.com/ISRCTN16491505

Keywords: Magnetic Resonance Imaging, Facioscapulohumeral muscular dystrophy type 1, Myotonic dystrophy type 2, Fat, Fibrosis, Remodeling

\section{Introduction}

Muscular dystrophy (MD) is a group of genetic and progressive diseases with primary symptoms of skeletal muscle pain and weakness. In some MD, such as Duchenne muscular dystrophy (DMD) and Becker muscular dystrophy (BMD), cardiac involvement is well known. Myocardial fibrosis detected by cardiovascular magnetic resonance (CMR) enables the prediction of cardiac events in DMD/BMD patients independently when compared with reduced left ventricular (LV) ejection fraction (LVEF). Interestingly, in patients with preserved LVEF, there is added value of focal fibrosis [1-3]. Focal fibrosis may occur in up to $90 \%$ of these patients, leading to heart failure and sudden cardiac death (SCD) in some cases [4].

Myotonic dystrophy type II (MD2) and facioscapulohumeral muscular dystrophy type 1 (FSHD1) have gained an increasing awareness during the last years. There is a suspicion that MD2 as well as FSHD1 could be underdiagnosed due to frequently mild symptoms and slower progression in females. Late onset and a slower progression seem to lead to a rate of $20 \%$ misdiagnosed patients [5]. MD2 and FSHD1 are mainly recognized as muscular diseases with rare cardiac involvement.
MD2 is an autosomal dominant inherited multisystemic muscle disease. The mutation frequency constitutes 1:1830 [6]. Patients often notice the first symptoms quite late, at the age of $37 \pm 15$ years [7], suffering from muscle weakness, myotonia and muscle pain.

FSHD1 is an autosomal dominant disorder and the third most common inherited muscle disease with an incidence of 1: 8.000-1: 20.000 [8]. Diagnosis of FSHD1 is often suspected in patients with presence of progressive asymmetric weakness of the face and shoulder muscles. However, $10-25 \%$ of patients are wheelchairdependent [9].

Arrhythmias in both patient groups are known but its relation to myocardial injury as well as evidence for progression of myocardial changes still remains unknown. Trevisan et al. reported arrhythmic events in $12 \%$ of FSHD-patients [10], whereas in MD2 different forms of arrhythmias were reported in $17 \%$ to $36 \%$ of patients [11].

In our pilot studies, we were able to identify myocardial injury, like fat infiltration and focal fibrosis, in over $26 \%$ of MD2 and FSHD1 patients with preserved LVEF $[12,13]$.

Table 1 Overview of muscular dystrophies and their associated cardiac abnormalities

\begin{tabular}{|c|c|c|c|c|c|}
\hline \multirow[t]{3}{*}{ Disease } & \multicolumn{5}{|c|}{ Cardiologic manifestations } \\
\hline & \multicolumn{3}{|l|}{ Clinical } & \multicolumn{2}{|l|}{ CMR } \\
\hline & $\begin{array}{l}\text { Cardiac } \\
\text { involvement } \\
(\%)\end{array}$ & $\begin{array}{l}\text { Possible phenotype } \\
\text { of the involvement }\end{array}$ & $\begin{array}{l}\text { Conduction disturbances/ } \\
\text { Arrhythmias }\end{array}$ & $\begin{array}{l}\text { Extension } \\
\text { of late } \\
\text { gadolinium } \\
\text { enhancement }\end{array}$ & $\begin{array}{l}\text { Presence } \\
\text { of fat } \\
\text { infiltration }\end{array}$ \\
\hline $\begin{array}{l}\text { Duchenne muscular } \\
\text { dystrophy }\end{array}$ & Up to 90 & DCM & $\begin{array}{l}\text { Sinus tachycardia, Ventricular tachy- } \\
\text { cardias }\end{array}$ & +++ & + \\
\hline Becker muscular dystrophy & $60-70$ & DCM & AV nodal and bundle branch blocks & +++ & No data \\
\hline Emery-Dreifuss muscular dystrophy & $50-90$ & $\begin{array}{l}\text { DCM, HCM, LVNC, } \\
\text { biatrial dilation }\end{array}$ & $\begin{array}{l}\text { Bradycardias (AV blocks), Tachycardias } \\
\text { (SVTs) }\end{array}$ & $\begin{array}{l}\text { Rare, if present } \\
\text { associated with } \\
\text { tachycardias }\end{array}$ & Rare \\
\hline Limb girdle muscular dystrophy & $25-90$ & DCM, HCM & SVTs, Ventricular tachycardia & ++ & + \\
\hline Myofibrillar myopathy & $40-60$ & DCM, HCM, LVNC & Complete AV Block & no data & No data \\
\hline $\begin{array}{l}\text { Facioscapulohumeral muscular } \\
\text { dystrophy }\end{array}$ & $5-25$ & DCM (rare) & RBBB, SVTs & $+/++$ & + \\
\hline Myotonic dystrophy type 1 & $60-80$ & DCM, HCM & $\begin{array}{l}\text { AV Blocks, RBBB/LBBB QTc/QRS prolon- } \\
\text { gation, PVC, Ventricular Tachycardia, } \\
\text { Atrial fibrillation, Atrial flutter }\end{array}$ & ++ & No data \\
\hline Myotonic dystrophy type 2 & Up to 25 & DCM, HCM & Atrial fibrillation & $+/++$ & + \\
\hline
\end{tabular}




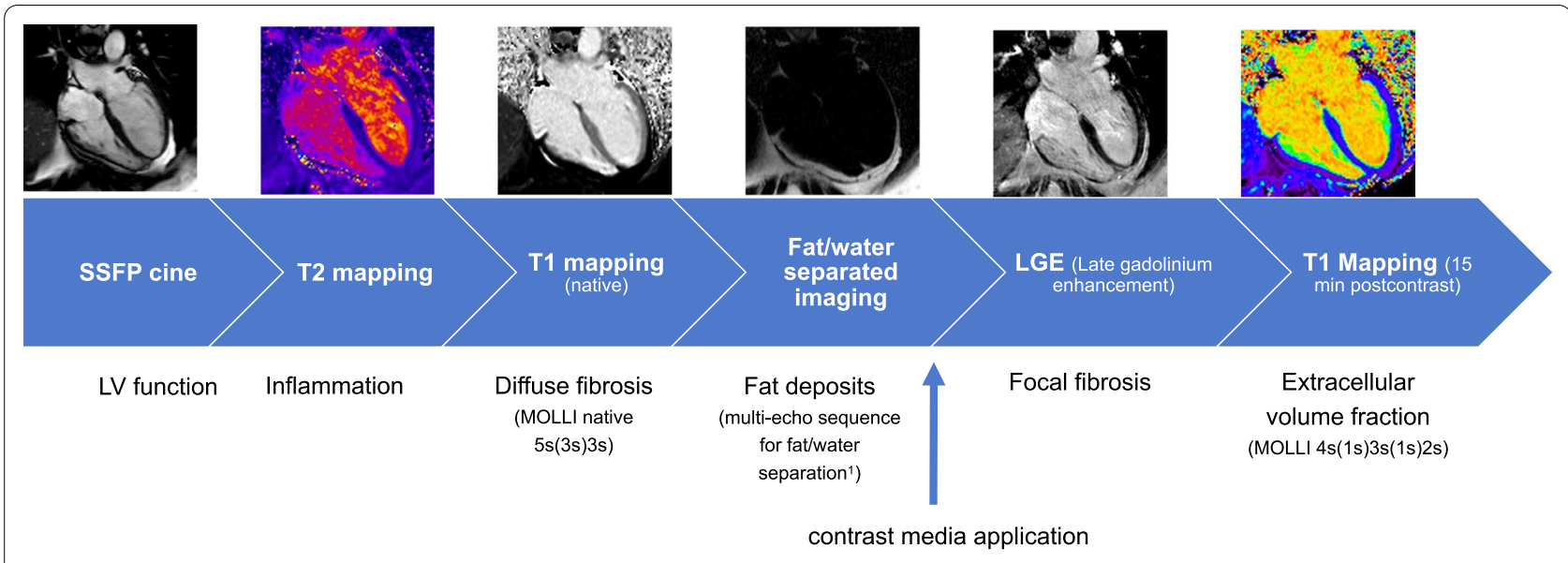

Fig. 1 Scan protocol

Due to individual predispositions, even mild initial dysfunction may lead to severe heart failure over months to years $[14,15]$. However, systematic follow-up analysis in patients with MD2 and FSHD1 are lacking. Table 1 provides an overview of the most common muscular dystrophies and their associated cardiac abnormalities.

The aim of this study was to investigate a potential progression of the cardiac remodeling processes, including focal myocardial injury and function, in patients with MD2 and FSHD1 by applying serial CMR. Furthermore, we evaluated its relation to arrhythmias and conduction abnormalities.

\section{Methods}

Follow-up was performed in 83 patients with genetically confirmed diagnosis of MD2 and FSHD1 who had previously participated in our studies [12,13].

A detailed medical history was recorded including symptoms related to cardiovascular diseases, medication and cardiovascular risk factors. Known myocardial infarction or myocarditis were considered as exclusion criterion to avoid an overlap with myocardial injury due to a different cause. Blood pressure was taken before and after CMR. Assessment of heart rhythm abnormalities was based on a 12-lead electrocardiogram (ECG) and on 24 h ECG-monitoring. Patients were also considered at risk of SCD according to the Groh-criteria: no sinus rhythm, PR interval $\geq 240 \mathrm{~ms}$, QRS duration $\geq 120 \mathrm{~ms}$, second- or third-degree atrioventricular block [16].

Significant arrhythmias were defined as frequent premature ventricular contractions (PVC $\geq 1000 / 24-h$ ), episodes of non-sustained ventricular tachycardia (NSVT), runs of supraventricular tachycardia (SVT) and 2nd/3rd degree atrioventricular (AV) block.
The local university ethical board approved the study (EA1/042/17) and all subjects gave written, informed consent.

\section{Cardiovascular magnetic resonance CMR protocol}

CMR was performed on a $1.5 \mathrm{~T}$ scanner (MAGNETOM AvantoFit ${ }^{\circledR}$, Siemens Healthineers, Erlangen, Germany) using a 32-channel surface coil.

Cine imaging was performed applying a balanced steady state free precession (bSSFP) sequence to determine the global cardiac performance. We acquired the following long axis views for the LV: four chamber (4Ch), three chamber (3Ch) and two chamber (2Ch) views and for the right ventricle (RV) a single long axis view (echo time (TE) $1.2 \mathrm{~ms}$; repetition time, $33 \mathrm{~ms}$; voxel size $1.8 \times 1.8 \times 6.0 \mathrm{~mm}^{3}$ ) as well as a short axis (SAx) package (TE $1.2 \mathrm{~ms}$; repetition time, $63 \mathrm{~ms}$; voxel size $1.4 \times 1.4 \times 7.0 \mathrm{~mm}^{3}$ ) to cover the LV.

For myocardial tissue differentiation parametric T1and T2-mapping, fat/water-separated imaging and focal fibrosis imaging (late gadolinium enhancement, LGE) were acquired. An overview of the scan protocol is provided in Fig. 1.

A multi-echo sequence was used for fat/water-separation [17] in 4ch view and five SAx slices (gradient echo sequence (GRE), double inversion recovery dark blood preparation, four echoes with monopolar readout, TR 824 ms, TE 1.6-3.9-6.2-8.6 ms, slice thickness $6 \mathrm{~mm}$ ).

We used the same contrast agent as in the previous studies $(0.2 \mathrm{mmol} / \mathrm{kg}$ body weight of gadoteridol for $\mathrm{MD} 2$ and $0.15 \mathrm{mmol} / \mathrm{kg}$ body weight of gadobutrol for FSHD1). [12, 13].

LGE was performed in the same slice position as cine imaging in $4 \mathrm{Ch}, 3 \mathrm{Ch}, 2 \mathrm{Ch}$ views and $\mathrm{SAx}$ orientations 
(gradient echo sequence, breath-held segmented protocol with $10 \mathrm{~ms}$ echo spacing, TE of $5.2 \mathrm{~ms}$, and slice thickness of $7 \mathrm{~mm}$ ) 10-15 min after administration of contrast agent.

T2- and T1-mapping were performed in basal, mid and apical slices as described $[12,18]$. Calculations were carried out for each segment and for each slice. Motioncorrected T2 mapping was based on a fast low angle shot (FLASH) gradient echo sequence in 4ch and SAx views as basal, mid-ventricular and apical slices. T2 maps were based on images with $\mathrm{T} 2$ preparation at times of 0/30/55 ms, and slice thickness of $6.0 \mathrm{~mm}$, TR $251.49 \mathrm{~ms}$ and TE $1.32 \mathrm{~ms}$.

Motion-corrected T1 mapping based on Modified Look-Locker Inversion Recovery (MOLLI) technique was performed before and $15 \mathrm{~min}$ after contrast media application using for T1 native: $5 \mathrm{~s}(3 \mathrm{~s}) 3 \mathrm{~s}$ and for T1 post-contrast: $4 \mathrm{~s}(1 \mathrm{~s}) 3 \mathrm{~s}(1 \mathrm{~s}) 2 \mathrm{~s}$ pattern in $4 \mathrm{Ch}$ view and three SAx views with basal, mid-ventricular and apical slices (imaging parameters: $\mathrm{TR}=281.64 \mathrm{~ms}$ (4ch) and $332.67 \mathrm{~ms}$ (SAX), TE $=1.12 \mathrm{~ms}$, slice thickness $6.0 \mathrm{~mm}$, GRAPPA acceleration factor 2).

\section{Data analysis}

In the first paper (2016) we used cvi42 (version 4.1.2, Circle Cardiovascular Imaging, Calgary, Alberta, Canada). The analysis of the MD2 cohort at follow-up was performed in 2018/2019. At that timepoint, we switched to cvi42 (version 5.3.2, Circle Cardiovascular Imaging). Because of potential influences and possible inconsistencies between different software versions, a quality assurance test was performed (re-evaluation of the baseline results with the new version in a randomly chosen subgroup). There were no significant differences between the quantitative results. For the FSHD1 group we used the same version of Circle software (version 5.3.2, Circle Cardiovascular Imaging) for both baseline and follow up evaluations.

SAx cine images were used to determine LVEF and right ventricular (RV) ejection fraction (RVEF), volumes and LV mass by drawing endo- and epicardial contours (papillary muscles as part of the mass) at the end of the systolic and diastolic phases [19].

We quantified the left atrium (LA) area based on the biplanar approach using 2- and 4ch. For right atrium (RA) quantification 4Ch view cine images in LV systole were used. Furthermore, LA volume and ejection fraction were quantified based on the biplanar approach [20].

The quantitative analysis of mapping was performed as average value for slice as well as for each segment. The region-of-interest ROI was defined by the delineation of the endocardial and epicardial border of the myocardium. To ensure that blood or extra myocardial tissue were not included, endo- and epicardial offset of 5\% was used. The segments were defined following the American Heart Association (AHA) segment model. The qualitative survey implied the exclusion of segments in case of artifacts (e.g., caused by susceptibility effects or unintended thoracic motion) or wrong motion correction.

The visual evaluation of the LGE images was performed by two independent, experienced readers (SCMR Level III) to assess presence, number and location of focal scars.

Quantification of LGE was performed with the established semi-automated signal threshold versus reference mean (STRM) method [21]. On all LGE images, endocardial and epicardial contours were manually traced and ROIs were defined in hyperenhanced and remote myocardium.

LGE was defined as myocardial signal intensity plus 3 standard deviations (SD) above remote, normal-appearing myocardium. The automated LGE detection could be manually corrected by the reader for a specific location to exclude obvious artifacts. After segmentation, myocardial and scar tissue (in \%) were calculated [21,22].

Fibrosis volume and the total cell volume were derived using extracellular volume fraction (ECV) and the following formulas [23]:

$$
\begin{aligned}
& \text { Fibrosis volume }=E C V * L \text { Vmass } / \text { myocardial density* } \\
& \text { Cell volume }=((1-E C V) * L V \text { mass }) / \text { myocardial density } * \\
& * \text { myocardial density }=1.05 \mathrm{~g} / \mathrm{m} .
\end{aligned}
$$

Fat/water-separation imaging was analyzed using predefined criteria. A suspected region was considered positive if the intramyocardial fat was detectable (a) in the fat-separated image (hyperintense) and in the water-separated image (hypointense) or (b) detected in one of the separated images as well as in the cine imaging and LGE. Within the LV segmental analysis was performed following the AHA segment model [24].

Global longitudinal strain (GLS) using CMR feature tracking was assessed from the $4 \mathrm{Ch}, 3 \mathrm{Ch}$, and $2 \mathrm{Ch}$ images. Endo- and epicardial contours were manually drawn in end-diastolic phase, defined as the phase with the largest LV volume. Trabeculae, papillary muscles, pericardium, and epicardial fat were consequently excluded from contouring [25].

\section{Statistical analysis}

The statistical analysis was performed using SPSS $^{\circledR}$ (version 25, Statistical Package for the Social Sciences, International Business Machines, Inc., Armonk, New 
Table 2 Characteristics of patients with muscular dystrophy ॥ (MD2) at follow-up

\begin{tabular}{llll}
\hline & \multicolumn{3}{l}{$\begin{array}{l}\text { Presence of Late Gadolinium } \\
\text { Enhancement }\end{array}$} \\
\cline { 2 - 4 } & All (n=22) & No ( $\mathbf{n = 1 7 )}$ & Yes ( $\mathbf{n = 5}$ \\
\hline Age (years) & $58 \pm 9$ & $57 \pm 9$ & $61 \pm 10$ \\
Male sex, $\mathrm{n}(\%)$ & $6(27.3)$ & 4 & 2 \\
Heart rate (beats per minute) & $69 \pm 9$ & $68 \pm 9$ & $72 \pm 11$ \\
Systolic BP (mmHg) & $130 \pm 16$ & $127 \pm 16$ & $139 \pm 16$ \\
Diastolic BP (mmHg) & $75 \pm 10$ & $73 \pm 10$ & $81 \pm 9$ \\
Arterial hypertension, $\mathrm{n}(\%)$ & $7(31.8)$ & 4 & 3 \\
Hyperlipidemia, $\mathrm{n}(\%)$ & $16(72.7)$ & 13 & 3 \\
Diabetes mellitus, $\mathrm{n}(\%)$ & $3(13.6)$ & 3 & - \\
Smoking, $\mathrm{n}(\%)$ & $2(9.1)$ & 1 & 1 \\
Cardiac symptoms & & & \\
Asymptomatic, $\mathrm{n}(\%)$ & $16(72.7)$ & 11 & 2 \\
Palpitations, $\mathrm{n}(\%)$ & $6(27.3)$ & 4 & 2 \\
Chest pain, $\mathrm{n}(\%)$ & $1(4.5)$ & 1 & 0 \\
Fatigue, $\mathrm{n}(\%)$ & $5(22.7)$ & 4 & 1 \\
\hline
\end{tabular}

Data are shown as mean values \pm standard deviation (SD) according to the AHAsegment model. BP blood pressure

York, USA). All results are shown as mean \pm standard deviation. Normal distribution was analyzed graphically using the Kolmogorov-Smirnov test. For comparing FSHD1/MD2 patients before and after the follow-up period we used the Mann-Whitney-U test. A $\mathrm{p}$ value $<0.05$ was considered to indicate a statistically significant difference. Intra- and inter-observer reproducibility was analyzed using intra-class correlation coefficient (ICC) and 95\% confidence interval (CI). ICC was classified as poor $(\mathrm{ICC}<0.4)$, good $(\mathrm{ICC}=0.4-$ $0.75)$ or excellent $(\mathrm{ICC}>0.75)$. Images were analyzed twice by blinded readers.

\section{Results}

\section{CMR analysis in MD2 and FSHD1 patients}

Follow-up was available for 27 of 31 MD2 (87\%) patients (follow up $3.9 \pm 0.3$ years) and 41 of $52(80 \%)$ FSHD1 patients (follow up $2.0 \pm 0.1$ years). Six patients refused follow-up CMR. Twenty-two patients with MD2 and 40 subjects with FSHD1 underwent CMR with contrast. Baseline characteristics of patients at follow-up are shown in Tables 2 and 3. Some patients during the observation period received medications that could reduce the progression of cardiac remodeling and fibrotic processes: 10/22 MD2 and 7/41 FSHD1 patients received angiotensin converting enzyme (ACE) inhibitors or angiotensin receptor blockers (ARBs), only 3 patients in both groups received $\beta$-blockers.
Table 3 Characteristics of patients with Facioscapulohumeral muscular dystrophy type 1 (FSHD1) at follow-up

\begin{tabular}{llll}
\hline & \multicolumn{3}{l}{$\begin{array}{l}\text { Presence of Late Gadolinium } \\
\text { Enhancement }\end{array}$} \\
\cline { 2 - 4 } & All (n=40) & No ( $\mathbf{n = 2 6 )}$ & Yes ( $\mathbf{n = 1 4 )}$ \\
\hline Age (years) & $49 \pm 14$ & $47 \pm 14$ & $54 \pm 11$ \\
Male sex, $\mathrm{n}(\%)$ & $29(70.7)$ & $9(36)$ & $3(21.4)$ \\
Heart rate (beats per minute) & $74 \pm 13$ & $76 \pm 13$ & $71 \pm 14$ \\
Systolic BP (mmHg) & $129 \pm 15$ & $127 \pm 16$ & $132 \pm 15$ \\
Diastolic BP (mmHg) & $79 \pm 10$ & $79 \pm 9$ & $79 \pm 11$ \\
Arterial hypertension, $\mathrm{n}(\%)$ & $8(20)$ & 1 & 7 \\
Hyperlipidemia, $\mathrm{n}(\%)$ & $7(17.5)$ & 3 & 4 \\
Diabetes mellitus, $\mathrm{n}(\%)$ & $3(7.5)$ & 1 & 2 \\
Smoking, $\mathrm{n}(\%)$ & $5(12.5)$ & 3 & 2 \\
Cardiac symptoms & & & \\
Asymptomatic, $\mathrm{n}(\%)$ & $29(70.7)$ & 19 & 10 \\
Palpitations, $\mathrm{n}(\%)$ & $8(12.2)$ & 6 & 2 \\
Chest pain, $\mathrm{n}(\%)$ & $1(2.4)$ & 1 & 0 \\
Fatigue, $\mathrm{n}(\%)$ & $6(14.6)$ & 4 & 2 \\
\hline
\end{tabular}

Data are shown as mean values \pm standard deviation (SD) according to the AHAsegment model. $B P$ blood pressure

\section{Myotonic dystrophy type II}

Individual and mean changes between both baseline and follow-up groups are displayed in Fig. 2.

\section{Remodeling}

Left ventricular and right ventricular chamber anatomy

LVEF stayed within normal range, however was statistically lower at follow up $\left(\mathrm{LVEF}_{\text {baseline }} 68 \pm 6 \% \mathrm{vs} \mathrm{LVEF}_{\mathrm{FU}}\right.$ $62 \pm 6 \%, \mathrm{p}=0.001$ ). After a mean observational period of four years, MD2 patients presented with significantly lower and mildly impaired RVEF compared to their baseline examinations $\left(\mathrm{RVEF}_{\text {baseline }} 59 \pm 7\right.$ vs $\mathrm{RVEF}_{\mathrm{FU}}$ $54 \pm 4 \%, \mathrm{p}=0.001)$. Both ventricles showed no significant changes in volume during the course of time (LV enddiastolic volume (LVEDV) $\mathrm{p}=0.605$ and indexed LVEDV (LVEDVI) $\mathrm{p}=0.275$, RVEDV $\mathrm{p}=0.444$ and RVEDVI $\mathrm{p}=0.456$.) (Table 4).

At follow up patients with focal fibrosis showed significantly lower LVEF $\left(\operatorname{LVEF}_{\mathrm{LGE}+} 59 \pm 2 \%\right.$ vs $\mathrm{LVEF}_{\mathrm{LGE}}$ $64 \pm 4 \%, \mathrm{p}=0.005)$, however it still remained in normal ranges. LVEDV and LVEDVI did not change at follow up $\left(\operatorname{LVEDV}_{\mathrm{LGE}+} 142 \pm 38\right.$ vs LVEDV $_{\text {LGE- }} 119 \pm 25 \mathrm{ml}$ $\mathrm{p}=0.127, \mathrm{LVEDVI}_{\mathrm{LGE}+} 0.81 \pm 0.19 \mathrm{ml} / \mathrm{m}^{2}$ vs LVEDVI $\mathrm{LGE}_{\mathrm{LE}}$ $0.70 \pm 0.13, \mathrm{p}=207)$.

\section{Left atria and right atria quantification}

We observed significant increase of the LA and RA areas (LA baseline $21 \pm 3$ vs LA $\mathrm{FU} 24 \pm 5 \mathrm{~cm}^{2}, \mathrm{p}=0.014$, RA 


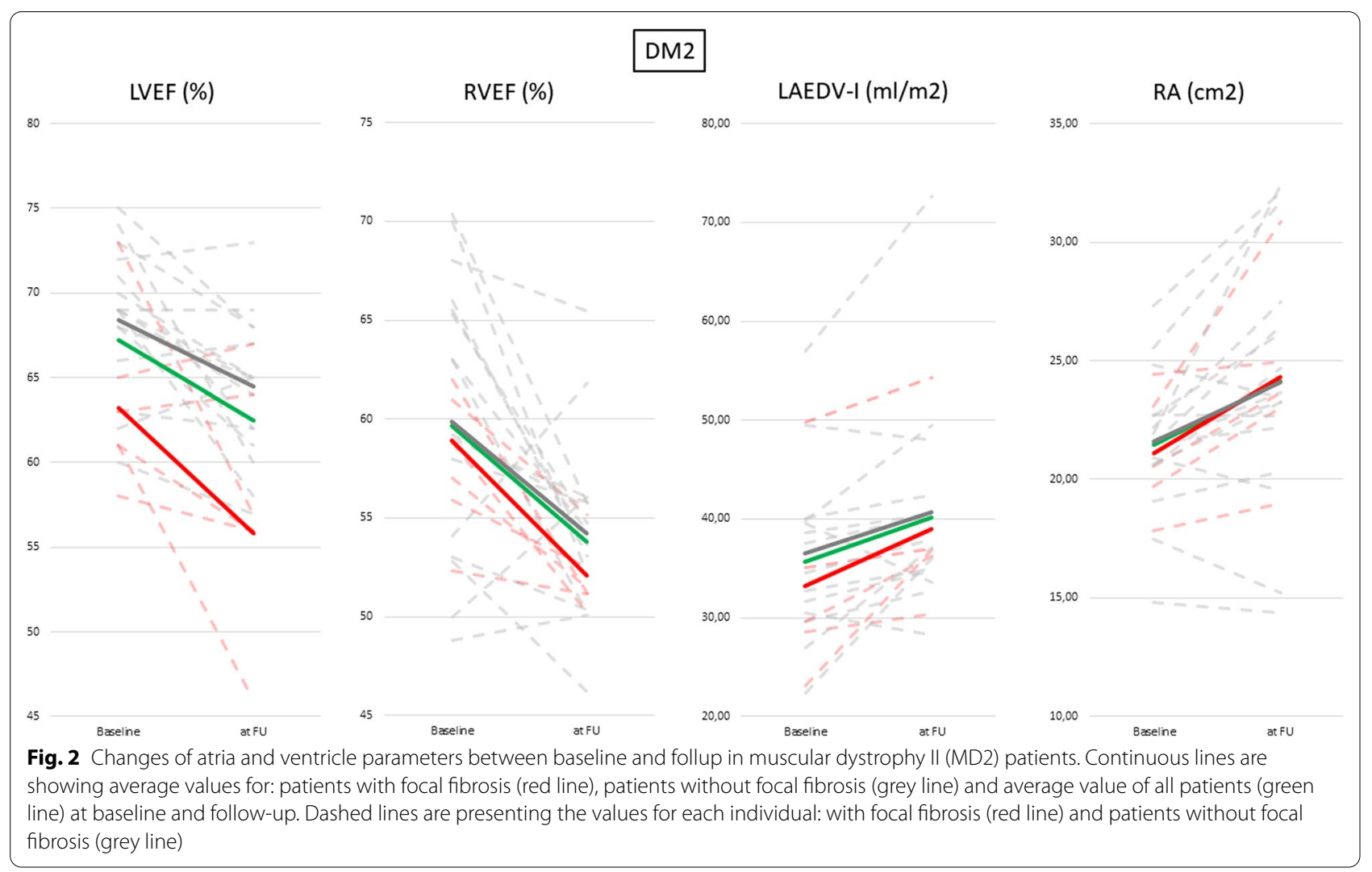

baseline $21 \pm 3$ vs RA FU $24 \pm 5 \mathrm{~cm}^{2}, \mathrm{p}=0.040$ ), however LA volume showed no significant changes (for LAEDV $\mathrm{p}=0.275$ and for LAEDVI $\mathrm{p}=0.288$ ) (Table 4).

We observed an excellent intra- and inter-observer reproducibility for ventricular and atrial assessment in both groups. ICC was 0.091 for intra-observer and 0.892 for inter-observer analysis.

\section{Myocardial tissue differentiation \\ Parametric mapping, cell and fibrosis volume}

We performed T2 and T1 mapping at baseline and during follow-up. Native T1 values remained stable (MD2: basal $p=0.066$, mid $p=0.258$, apical $p=0.163)$, but ECV dropped significantly (MD2: basal $\mathrm{p}=0.014$, mid $\mathrm{p}<0.01$, apical $\mathrm{p}<0.01)$. T2 decreased significantly as well (MD2: basal $\mathrm{p}<0.01$, mid $\mathrm{p}<0.01$, apical $\mathrm{p}<0.01)$.

While the cell volume remained constant, patients at follow-up presented with lower fibrosis volume (MD2 cell volume basal $\mathrm{p}=0.409$, mid $\mathrm{p}=0.553$; fibrosis volume basal $\mathrm{p}=0.055$, mid $\mathrm{p}=0.009)$ (Table 4).

\section{Focal fibrosis and its relation to cardiac remodeling}

In the MD2 group, new focal fibrosis could be identified in 1 of 22 patients, (5\%, female) at follow up. It was located in the basal segments of the inferolateral and inferoseptal wall. At follow-up, an increase of focal fibrosis was observed. In total 6/22 (27\%,3 women) MD2 patients had focal fibrosis (see Fig. 3 and Table 5).

\section{Focal fat}

New focal fat infiltration was observed in 2 of 22 patients (10\%, both females), mostly located in the apical part of the interventricular septal wall (Fig. 4). Overall, fat infiltration was present in $7 / 22(32 \%$, all females) patients at follow-up.

\section{Myocardial deformation- global longitudinal strain (GLS)}

GLS was significantly lower in MD2 patients at follow in comparison to baseline $\left(\mathrm{GLS}_{\mathrm{MD} 2 \mathrm{LGE}(-)}\right.$ baseline $-17.9 \pm 1.0 \%$ vs. $\left.\mathrm{GLS}_{\mathrm{MD} 2 \mathrm{LGE}(-) \text { at follow up }}-16.8 \pm 4.0 \%, \mathrm{p}<0.01\right)$. LGE $(+)$ patients were excluded to avoid the influence of known focal fibrosis.

\section{Heart rhythm abnormalities and its relation to myocardial tissue changes}

12-lead ECG was available in all patients, Holter-ECG in 24/27 patients.

New arrhythmic events or conduction abnormalities were recorded in 10/27 patients (37\%). New episodes of SVT occurred in 7 patients while a new AV block type 2 
Table 4 CMR parameters of patients with MD2 and FSHD1 at baseline and at follow-up

\begin{tabular}{|c|c|c|c|c|c|c|}
\hline \multirow[t]{2}{*}{ Parameter } & \multicolumn{3}{|l|}{ MD2 } & \multicolumn{3}{|l|}{ FSHD1 } \\
\hline & Baseline $(n=31)$ & Follow-up $n=22$ & p-value & Baseline $n=52$ & $\begin{array}{l}\text { Follow-up } \\
n=41\end{array}$ & $p$ value \\
\hline LVEF (\%) & $68 \pm 6$ & $62 \pm 6$ & $<0.01$ & $63 \pm 5$ & $60 \pm 3$ & 0.762 \\
\hline $\operatorname{LVEDV}(m l)$ & $126 \pm 22$ & $124 \pm 29$ & 0.605 & $128 \pm 21$ & $139 \pm 34$ & 0.131 \\
\hline LVEDVI $(\mathrm{ml} / \mathrm{cm})$ & $0.80 \pm 0.11$ & $0.73 \pm 0.15$ & 0.275 & $0.70 \pm 0.10$ & $0.79 \pm 0.17$ & $<0.01$ \\
\hline LV mass (g) & $104 \pm 27$ & $92 \pm 24$ & 0.124 & $99 \pm 25$ & $102 \pm 24$ & 0.630 \\
\hline LV mass index $(\mathrm{g} / \mathrm{cm})$ & $0.60 \pm 0.14$ & $0.54 \pm 0.12$ & 0.110 & $0.56 \pm 0.13$ & $0.57 \pm 0.12$ & 0.524 \\
\hline LV stroke volume $(m l)$ & $85 \pm 13$ & $78 \pm 17$ & 0.113 & $80 \pm 15$ & $84 \pm 18$ & 0.084 \\
\hline LV stroke volume index $\left(\mathrm{m} / / \mathrm{m}^{2}\right)$ & $46 \pm 6$ & $42 \pm 6$ & 0.063 & $45 \pm 8$ & $48 \pm 9$ & 0.245 \\
\hline $\operatorname{RVEF}(\%)$ & $59 \pm 7$ & $54 \pm 4$ & $<0.01$ & $51 \pm 6$ & $49 \pm 5$ & 0.104 \\
\hline RVEDV $(m l)$ & $140 \pm 29$ & $146 \pm 33$ & 0.444 & $160 \pm 31$ & $169 \pm 28$ & 0.470 \\
\hline RVEDVI $\left(\mathrm{m} / / \mathrm{m}^{2}\right)$ & $76 \pm 15$ & $79 \pm 14$ & 0.456 & $83 \pm 16$ & $88 \pm 14$ & 0.422 \\
\hline RV stroke volume $(m l)$ & $82 \pm 18$ & $80 \pm 19$ & 0.932 & $76 \pm 18$ & $83 \pm 18$ & 0.082 \\
\hline RV stroke volume index $\left(\mathrm{m} / / \mathrm{m}^{2}\right)$ & $44 \pm 89$ & $43 \pm 8$ & 0.852 & $40 \pm 8$ & $43 \pm 8$ & 0.063 \\
\hline LAEF (\%) & $60 \pm 8$ & $57 \pm 7$ & 0.392 & $62 \pm 8$ & $60 \pm 7$ & 0.452 \\
\hline LAEDV $(m /)$ & $63 \pm 18$ & $71 \pm 25$ & 0.275 & $54 \pm 14$ & $61 \pm 14$ & 0.021 \\
\hline $\operatorname{LAEDVI}\left(\mathrm{ml} / \mathrm{m}^{2}\right)$ & $35 \pm 8$ & $38 \pm 25$ & 0.288 & $28 \pm 7$ & $32 \pm 8$ & 0.027 \\
\hline $\mathrm{LA}\left(\mathrm{cm}^{2}\right)$ & $21 \pm 3$ & $24 \pm 5$ & $<0.01$ & $19 \pm 3$ & $22 \pm 3$ & $<0.01$ \\
\hline $\mathrm{RA}\left(\mathrm{cm}^{2}\right)$ & $21 \pm 3$ & $24 \pm 5$ & 0.040 & $20 \pm 3$ & $23 \pm 4$ & 0.029 \\
\hline Native T1 basal (ms) & $1029 \pm 30$ & $1015 \pm 38$ & $p=0.066$ & $1010 \pm 26$ & $991 \pm 24$ & $<0.01$ \\
\hline Native T1 mid (ms) & $1012 \pm 38$ & $998 \pm 30$ & $p=0.258$ & $991 \pm 39$ & $989 \pm 30$ & $p=0.102$ \\
\hline Native T1 apical (ms) & $1018 \pm 50$ & $999 \pm 32$ & $p=0.163$ & $983 \pm 41$ & $970 \pm 40$ & $p=0.203$ \\
\hline ECV basal (\%) & $26 \pm 3$ & $24 \pm 3$ & $<0.01$ & $26 \pm 3$ & $22 \pm 2$ & $<0.01$ \\
\hline ECV mid (\%) & $26 \pm 2$ & $24 \pm 2$ & $<0.01$ & $26 \pm 3$ & $23 \pm 3$ & $<0.01$ \\
\hline ECV apical (\%) & $29 \pm 3$ & $26 \pm 2$ & $<0.01$ & $27 \pm 3$ & $24 \pm 2$ & $<0.01$ \\
\hline T2 basal (ms) & $51 \pm 2$ & $49 \pm 2$ & $<0.01$ & $50 \pm 4$ & $47 \pm 2$ & $<0.01$ \\
\hline T2 mid (ms) & $52 \pm 3$ & $49 \pm 3$ & $<0.01$ & $51 \pm 3$ & $47 \pm 2$ & $<0.01$ \\
\hline T2 apical (ms) & $55 \pm 4$ & $50 \pm 2$ & $<0.01$ & $53 \pm 3$ & $48 \pm 2$ & $<0.01$ \\
\hline Cell volume basal (ml) & $72 \pm 18$ & $68 \pm 17$ & $p=0.409$ & $71 \pm 19$ & $74 \pm 22$ & $p=0.308$ \\
\hline Cell volume mid (ml) & $70 \pm 19$ & $76 \pm 17$ & $p=0.553$ & $71 \pm 20$ & $73 \pm 22$ & $p=0.361$ \\
\hline Fibrosis volume basal (ml) & $25 \pm 9$ & $20 \pm 7$ & $p=0.055$ & $24 \pm 8$ & $20 \pm 7$ & $p=0.023$ \\
\hline Fibrosis volume mid (ml) & $26 \pm 7$ & $21 \pm 6$ & $<0.01$ & $23 \pm 7$ & $22 \pm 7$ & $p=0.032$ \\
\hline GLS (\%) LGE(-) patients & $-17.9 \pm 1$ & $-16.8 \pm 1$ & $<0.01$ & $-18.3 \pm 1$ & $-16.4 \pm 1$ & $p<0.01$ \\
\hline
\end{tabular}

Data are shown as mean values \pm standard deviation (SD) according to the AHA-segment model. Significant differences ( $p<0.05)$ are highlighted in bold

$B M I$ body mass index, BSA body surface area (Mosteller), $H R$ heart rate, $B P$ blood pressure, $L V E F$ left ventricular ejection fraction, $L V E D V$ left ventricular end-diastolic volume, LVEDVI eft ventricular end-diastolic volume index, LVESV left ventricular end-systolic volume, LA left atrium, $R A$ right atrium, GLS global longitudinal strain, ECV extracellular volume fraction

was detected in only 1 patient. Two patients displayed new conduction abnormalities, specifically right bundle branch block and left anterior hemiblock. Positive Groh-criteria (AV block type 1) could be identified in only one patient. Arrhythmias or conduction disturbances were observed in all seven patients with fatty infiltrations and 4 of 6 patients with focal fibrosis. See Table 5.

\section{Facioscapulohumeral Muscular Dystrophy 1 (FSHD1)}

Individual and mean changes between baseline and follow-up in both groups are displayed in Fig. 5.

\section{Remodeling \\ Left ventricular and right ventricular chamber size and function}

During the follow up period, LVEF remained within the normal range $\left(\mathrm{LVEF}_{\text {baseline }} 63 \pm 5 \%\right.$ vs $\mathrm{LVEF}_{\mathrm{FU}} 60 \pm 3 \%$, $\mathrm{p}=0.762$ ). There was no significant progression of $\mathrm{RV}$ dysfunction, however RVEF in FSHD1 patients was mildly impaired $\left(\operatorname{RVEF}_{\text {baseline }} 51 \pm 6\right.$ vs $\operatorname{RVEF}_{\mathrm{FU}} 49 \pm 5 \%$, $\mathrm{p}=0.001)$. Volume in both ventricles stayed within normal range during the course of time, however LVEDVI increased significantly at follow-up (LVEDV $\mathrm{p}=0.131$ 

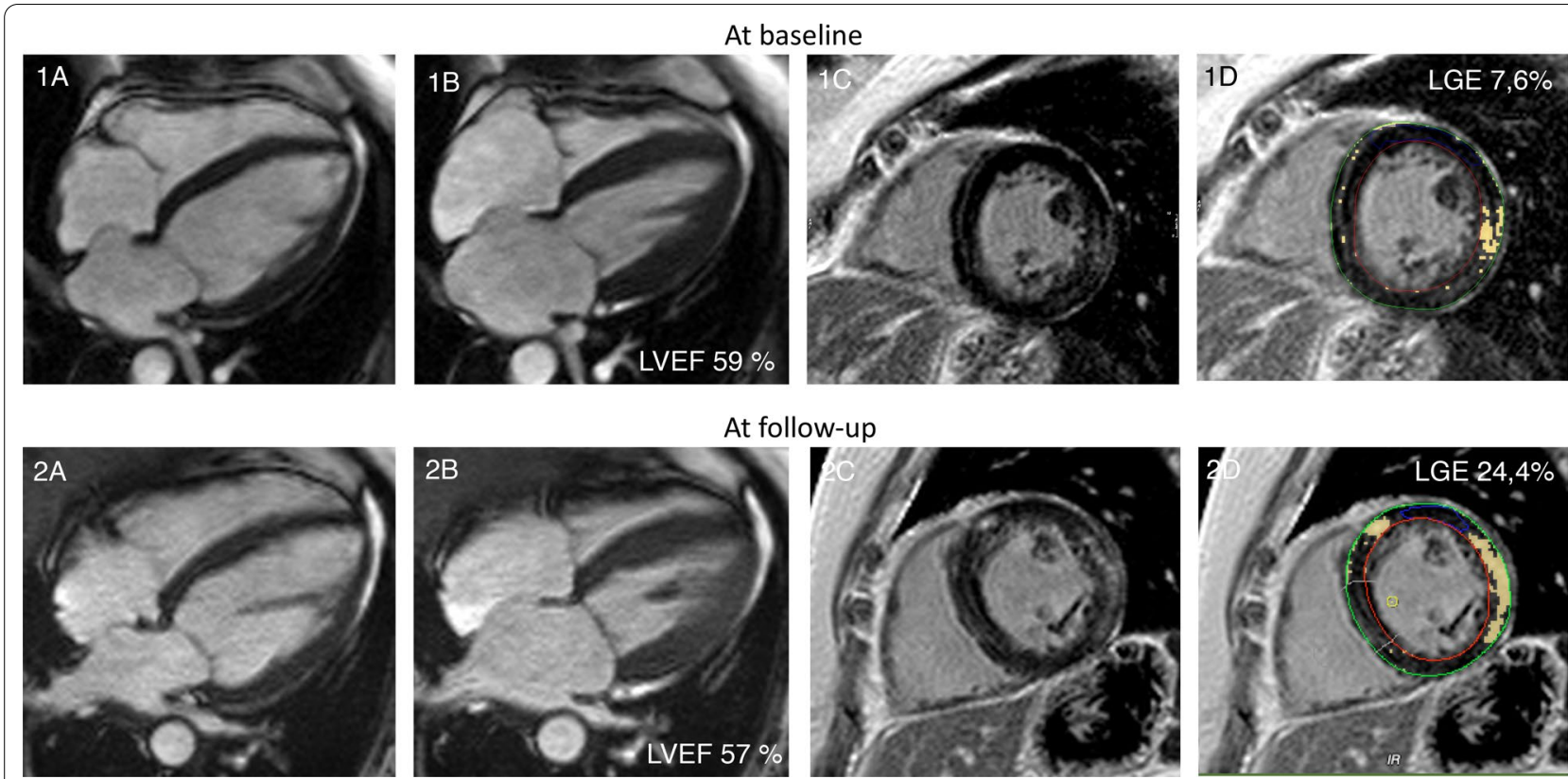

Fig. 3 MD2 patient with progressive intramyocardial fibrosis and conduction abnormalities (atria-ventricular (AV) Block l, left anterior hemiblock) and still preserved ejection fraction. 1A-1D at baseline. 2A-2D at follow-up. Cine images in 4ch in diastole $(\mathbf{1}, \mathbf{2} \mathbf{A})$ and systole $(\mathbf{1}, \mathbf{2} \mathbf{B})$. Late gadolinium enhancement (LGE) in short axis views $(\mathbf{1}, \mathbf{2} \mathbf{C}, \mathbf{D})$

and LVEDVI $\mathrm{p}=0.013$, RVEDV $\mathrm{p}=0.470$ and RVEDV-I $\mathrm{p}=0.422$; Table 4).

\section{Quantification of the left atria and right atria size}

We observed a significant progression of both LA and RA areas (LA baseline $19 \pm 3$ vs LA $\mathrm{FU} 22 \pm 3 \mathrm{~cm}^{2}, \mathrm{p}<0.001$, RA baseline $20 \pm 3$ vs RA $\left.\mathrm{FU}_{2} 23 \pm 4 \mathrm{~cm}^{2}, \mathrm{p}=0.029\right)$ as well as LA volume (for LAEDV $\mathrm{p}=0.271$ and for LAEDVI $\mathrm{p}=0.227$ ).

\section{Myocardial tissue differentiation \\ Parametric mapping, cell and fibrosis volume}

We performed T2 and T1 mapping at baseline and during follow-up. Native T1 values dropped in basal slices but remained stable in mid and apical slices (FSHD1: basal $\mathrm{p}=0.001$, mid $\mathrm{p}=0.102$, apical $\mathrm{p}=0.203$ ). ECV dropped significantly within three whole slices (basal $\mathrm{p}<0.001$, mid $\mathrm{p}<0.001$, apical $\mathrm{p}<0.001$ ). T2 mapping values decreased significantly similarly as in MD2 patients (basal $\mathrm{p}<0.001$, mid $\mathrm{p}<0.001$, apical $\mathrm{p}<0.001$ ). Interestingly, we observed the same phenomenon to that in MD2 patients regarding the cell and fibrosis volume. While the cell volume remained constant, patients at follow-up presented a statistically lower volume of fibrosis (cell volume $\mathrm{p}=0.306$, mid $\mathrm{p}=0.361$, fibrosis volume basal $\mathrm{p}=0.023$, mid $p=0.032$ ). We included detailed information in the table with the CMR parameters (Table 4).

\section{Focal fibrosis and its relation to cardiac remodeling}

In the FSHD1 group, new focal fibrosis was detected in 2 of 40 patients $(6 \%$, male). The fibrosis was located inferolateral and inferoseptal. Overall, in 15 of 40 (37\%, 3 females) patients focal fibrosis could be identified. The pattern of the fibrosis was non-ischemic with an intramural and subepicardial distribution (Fig. 6). During the follow-up we also observed a quantitative increase in focal fibrosis (Table 5).

At follow up, patients with focal fibrosis showed no significant changes in LVEF $\left(\mathrm{LVEF}_{\mathrm{LGE}+} 60 \pm 7 \%\right.$ vs $\mathrm{LVEF}_{\mathrm{LGE}-}$ $60 \pm 6 \%, \mathrm{p}=0.356$ ), as well as in LVEDV and LVEDVI $\left(\mathrm{LVEDV}_{\mathrm{LGE}+} 152 \pm 46\right.$ vs LVEDV $_{\mathrm{LGE}-} 132 \pm 23 \mathrm{ml}$ $\mathrm{p}=0.242, \mathrm{LVEDVI}_{\mathrm{LGE}+} 0.86 \pm 0.23 \mathrm{ml} / \mathrm{m}^{2}$ vs LVEDVI $\mathrm{LGE}_{\text {- }}$ $0.74 \pm 0.10, \mathrm{p}=131)$.

\section{Focal fat}

New focal fat infiltration was observed in 5 of 40 patients (13\%, 1 female). Majority was located in the apical part of the interventricular septal wall. In one patient the infiltration was found in the inferior wall (Fig. 7). Intramyocardial fat could be detected in 12 of 40 patients (30\%, 3 female).

\section{Myocardial deformation- global longitudinal strain (GLS)}

To avoid the influence of known focal fibrosis, after exclusion of LGE $(+)$ patients, GLS was significantly lower in FSHD1 patients at follow in comparison to 
Table 5 Clinical characteristics and imaging findings according to the distribution of late gadolinium enhancement (LGE) and fat infiltration in DM2 and FSHD1 patients at baseline and at follow-up

\begin{tabular}{|c|c|c|c|c|c|c|c|c|c|c|c|}
\hline \multirow{2}{*}{\multicolumn{2}{|c|}{ Type of Arrhythmias }} & \multicolumn{4}{|c|}{ All DM2 patients } & \multicolumn{3}{|c|}{ DM2 LGE (+) } & \multicolumn{3}{|c|}{ DM2 Fat $(+)$} \\
\hline & & \multicolumn{2}{|c|}{ Baseline $(n=32)$} & \multicolumn{2}{|c|}{ Follow-up $n=22$} & $\begin{array}{l}\text { Baseline } \\
(n=5)\end{array}$ & \multicolumn{2}{|c|}{$\begin{array}{l}\text { Follow-up } \\
n=6\end{array}$} & \multicolumn{2}{|c|}{ Baseline $n=6$} & \multirow{2}{*}{$\begin{array}{l}\begin{array}{l}\text { Follow-up } \\
\mathbf{n}=7\end{array} \\
5\end{array}$} \\
\hline \multicolumn{2}{|l|}{$\mathrm{SVT}(\mathrm{n})$} & \multicolumn{2}{|l|}{2} & \multicolumn{2}{|l|}{9} & - & \multicolumn{2}{|l|}{5} & \multicolumn{2}{|l|}{-} & \\
\hline \multicolumn{2}{|c|}{ Non-sustained VT n (n) } & \multicolumn{2}{|l|}{-} & \multicolumn{2}{|l|}{-} & - & \multicolumn{2}{|l|}{ - } & \multicolumn{2}{|l|}{-} & - \\
\hline \multicolumn{2}{|c|}{ Frequent PVC ( $\geq 1000 / 24 h)$ (n) } & \multicolumn{2}{|l|}{-} & - & & - & - & & - & & - \\
\hline AV Block I (n) & & 4 & & 5 & & 2 & 2 & & 2 & & 2 \\
\hline AV Block II (n) & & - & & 1 & & - & - & & - & & - \\
\hline LBBB & & 1 & & 1 & & 1 & 1 & & 1 & & 1 \\
\hline RBBB & & 1 & & 2 & & - & 1 & & - & & - \\
\hline LAH & & 2 & & 3 & & - & 1 & & - & & - \\
\hline LGE location and glot & al volume & & & & & 5 & 6 & & & & \\
\hline Inferolateral basal ( $\mathrm{n}$ & & 5 & & 6 & & 5 & 6 & & 1 & & 3 \\
\hline Anterolateral basal ( & & - & & 2 & & - & 2 & & - & & - \\
\hline Septal (n) & & 1 & & 1 & & 1 & 1 & & - & & - \\
\hline LGE area - mean (\%) & & & & & & 8.4 & 17.6 & & & & \\
\hline Fat apical & & & & & & & & & 6 & & 7 \\
\hline Medical therapy & & & & & & & & & & & \\
\hline Beta blockers (n) & & 1 & & 3 & & - & 1 & & - & & 1 \\
\hline ACE, Sartans (n) & & 4 & & 10 & & 1 & 2 & & - & & 2 \\
\hline & All FSHL & tient & & & FSHD1 LGE (+) & & & & D1 Fat $(+)$ & & \\
\hline $\begin{array}{l}\text { Type of } \\
\text { Arrhythmias }\end{array}$ & Baseline & 52) & Follow-up & $=40)$ & Baseline $(n=13)$ & Follo & $p(n=15)$ & & eline $(n=7)$ & & $\begin{array}{l}\text { w-up } \\
12)\end{array}$ \\
\hline SVT (n) & 1 & & 8 & & 1 & 3 & & - & & & \\
\hline $\begin{array}{l}\text { Non-sustained VT } \\
\mathrm{n}(\mathrm{n})\end{array}$ & 1 & & 2 & & 1 & 2 & & 1 & & & \\
\hline $\begin{array}{l}\text { Frequent PVC } \\
(\geq 1000 / 24 h)(n)\end{array}$ & 2 & & 11 & & 1 & 8 & & 2 & & & \\
\hline AV Block I (n) & 1 & & 3 & & 1 & 1 & & - & & & \\
\hline AV Block II (n) & - & & - & & - & - & & - & & & \\
\hline LBBB & - & & - & & - & - & & - & & & \\
\hline RBBB & - & & - & & - & - & & - & & & \\
\hline $\mathrm{LAH}$ & - & & - & & - & - & & - & & & \\
\hline $\begin{array}{l}\text { LGElocation and } \\
\text { global volume }\end{array}$ & & & & & 13 & 15 & & 2 & & & \\
\hline $\begin{array}{l}\text { Inferolateral basal } \\
\text { (n)) }\end{array}$ & 7 & & 7 & & 7 & 7 & & - & & & \\
\hline $\begin{array}{l}\text { Anterolateral basal } \\
\text { (n) }\end{array}$ & 2 & & 1 & & 2 & 1 & & - & & & \\
\hline Septal (n) & 3 & & 3 & & 3 & 3 & & - & & & \\
\hline Inferior (n) & 1 & & 3 & & 1 & 3 & & - & & & \\
\hline LGE area - mean (\%) & & & & & 18.6 & 28.9 & & & & & \\
\hline Fat apical & & & & & & & & 7 & & 1 & \\
\hline Medical therapy & & & & & & & & & & & \\
\hline Beta blockers (n) & 1 & & 4 & & & 1 & & 1 & & & \\
\hline ACE-I, ARBs (n) & 2 & & 7 & & 1 & 3 & & 1 & & & \\
\hline
\end{tabular}

$\mathrm{SVT}=$ supraventricular tachycardia, $\mathrm{VT}=$ ventricular tachycardia, $\mathrm{PVC}=$ premature ventricular contractions, $\mathrm{LBBB}=$ left bundle branch block, $\mathrm{RBBB}=$ right bundle branch block, $\mathrm{LAH}=$ left anterior hemiblock, $\mathrm{LGE}=$ late gadolinium enhancement. $\mathrm{ACE}-\mathrm{I}=$ angiotensin-converting enzyme (ACE) inhibitors, ARBs = angiotensin II receptor blockers 

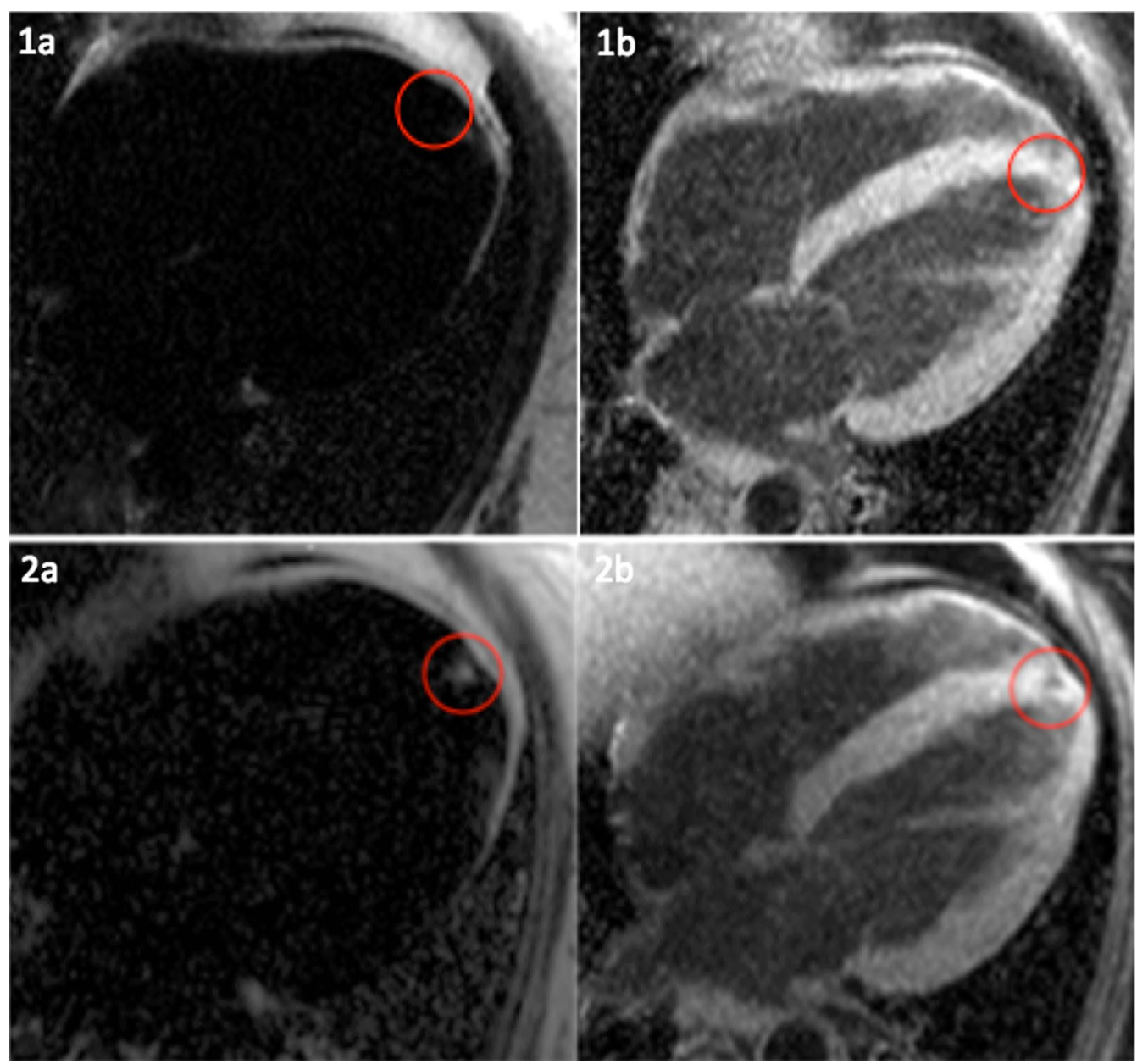

Fig. 4. 4-chamber view. Patient with MD2 and new apical fat infiltration. CMR 1: fat-separated image (1) and water-separated image (1) $)$ without evidence of fat infiltration. CMR 2: new apical fat infiltration, bright in the fat-separated image (2a) and hypointense (2b) in the water-separated image

baseline $\left(\mathrm{GLS}_{\mathrm{FSHD} 1 \mathrm{LGE}(-) \text { baseline }}-18.3 \pm 1 \%\right.$ vs. $\mathrm{GLS}_{\mathrm{FSHD} 1}$ LGE (-) at follow up $-16.4 \pm 1 \%, \mathrm{p}<0.01)$.

\section{Heart rhythm abnormalities and its relation to myocardial tissue changes}

12-lead ECG was available in all patients, Holter-ECG in 34 of 40 patients (85\%) with the diagnosis of FSHD1. The lack of data was due to patient related reasons.

New arrhythmic events were recorded in 10 of 34 patients (29\%). NSVT was detected in one patient, runs of SVT in eight patients. Groh-criteria could not be identified. Holter was not available in 5/34 patients with focal fibrosis and/or fat infiltration. Ventricular arrhythmias (PVC $>1000$ ) were observed in 8 patients with focal fibrosis and 3 patients with fat infiltration. SVTs were present in 5 patients with fatty infiltrations and 3 patients with focal fibrosis (Table 5).

\section{Discussion}

In this study, we demonstrate that cardiac remodeling is progressive in both MD2 and FSHD1. Even in the absence of significant cardiac symptoms we observed a progression of structural and functional changes regarding all cardiac chambers.

The incidence of myocardial tissue changes such as focal fibrosis and fat infiltration was also higher at follow-up. There seems to be a relationship between structural abnormalities and abnormal heart rhythms and conduction abnormalities/disturbances. To the best of our knowledge, this is the first follow-up study applying CMR in patients with MD2 and FSHD1.

In inherited neuromuscular disorders such as DMD and BMD the development of a cardiomyopathy and/or heart failure is the second most important cause of death after respiratory failure. LV focal fibrosis was described in approximately $70 \%$ of these patients [26, 27]. The 


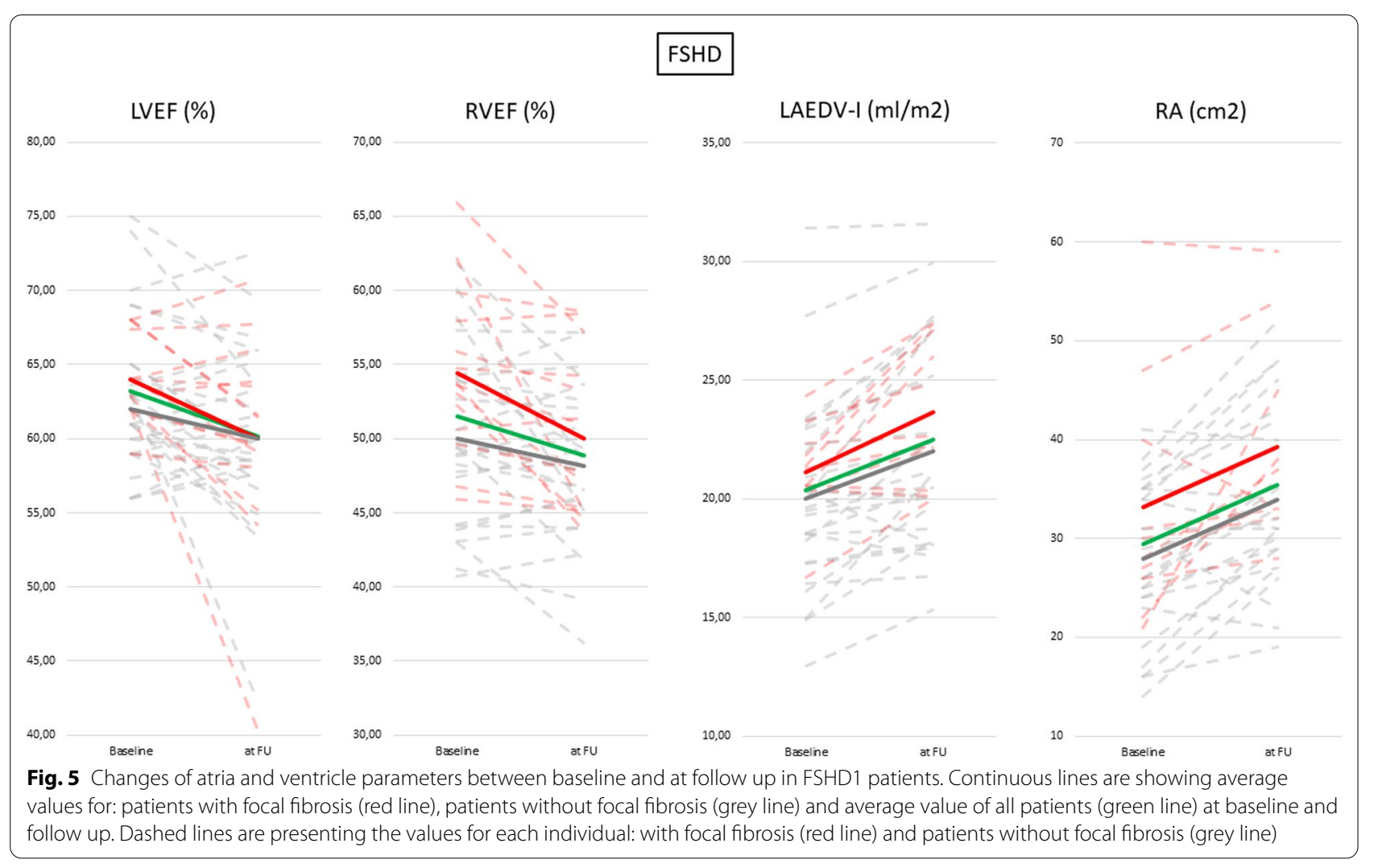

progression of myocardial fibrosis in other forms of MD are already well known [27, 28]. Furthermore, follow-up studies performed in DMD carriers showed progressive myocardial changes such as focal fibrosis and impaired LVEF [29]. In our study, we found that almost $30 \%$ of patients with MD2 and FSHD1 had focal fibrosis despite a preserved LVEF. However, in FSHD1 patients RVEF was mildly impaired starting already at baseline. During follow-up the remodeling of ventricle and atria was progressive. LV and RV functions worsened in both patient groups. Furthermore, we observed an increase of atrial size which was more evident in patients with known supraventricular arrhythmias. In almost $26 \%$ of patients with MD2, diabetes mellitus was already present at baseline. With this being a traditional cardiovascular risk factor associated with vascular events, it could contribute to cardiac remodeling, nevertheless all patients with focal fibrosis showed a non-ischemic LGE pattern.

Myocardial fat infiltration is a less studied matter in comparison to focal fibrosis as detection of fat by applying CMR is challenging. Thanks to recent technical developments identification of even small changes is feasible [17]. A correlation between fatty infiltration and arrhythmia frequency is already known in different diseases. Lu et al. reported the presence of myocardial fat in dilated cardiomyopathy (DCM) patients and its significant relationship to LV global function as well as a possible influence on the prognosis of DCM [30]. However, larger data sets are still missing and fatty remodeling seems to be underestimated and understudied. Fat within apical septum was reported also in healthy, however in our study focal fat infiltration was present in a much higher percentage of the studied cohort (30\% of MD2 and FSHD1 patients). Especially in our MD2 patient group, all arrhythmic events were associated with the presence of fatty infiltrations, possibly underlying the impact on conduction abnormalities as discussed below.

In most patients with MD the LV is affected, presenting with a dilatation or reduced LVEF. However, over a span of the last few years there has been increasing awareness of the potential impact of RV impairment. RV and atrial remodeling may also dominate with clinical manifestations in neuromuscular diseases. These findings are often combined with rhythm- and conduction abnormalities [31]. Cardiac conduction abnormalities and atrial tachyarrhythmias are commonly observed in inherited MD and may also evolve from myocardial remodeling [32]. In patients with myotonic dystrophy type 1 (MD1), rhythm and conduction abnormalities are the dominant features of cardiac involvement, while heart failure seems to not be the most frequent finding in this entity. Asymptomatic MD1 patients with Groh-criteria were at higher 

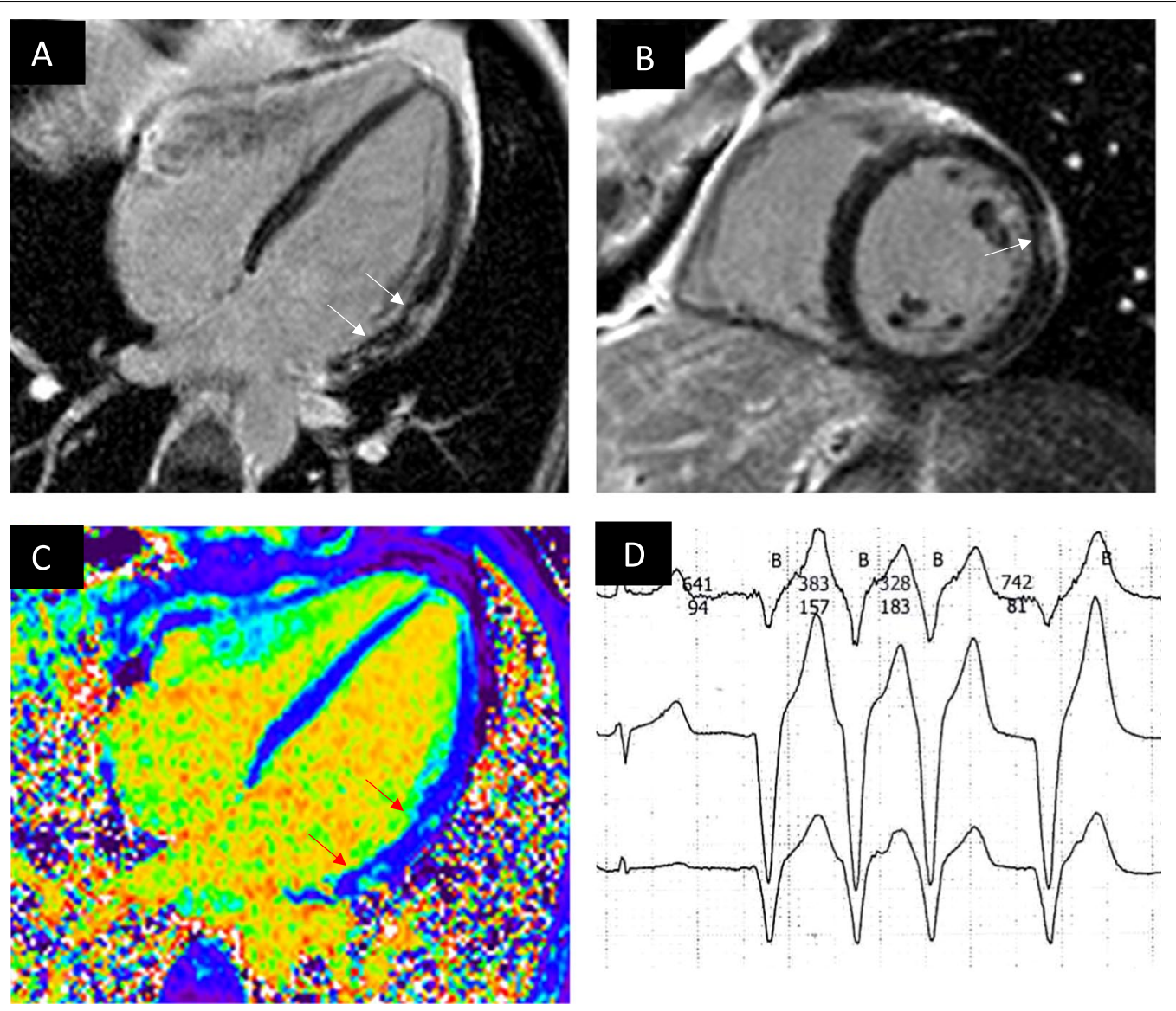

Fig. 6. 34-year-old asymptomatic man with FSHD1 presenting short episode of non-sustained ventricular tachycardia (VT) in Holter-ECG (4D) and evidence on LGE-CMR (LGE in 4Ch 4A and short axis 4B) involving LV lateral wall. Extracellular volume fraction (ECV) map in 4ch 4C
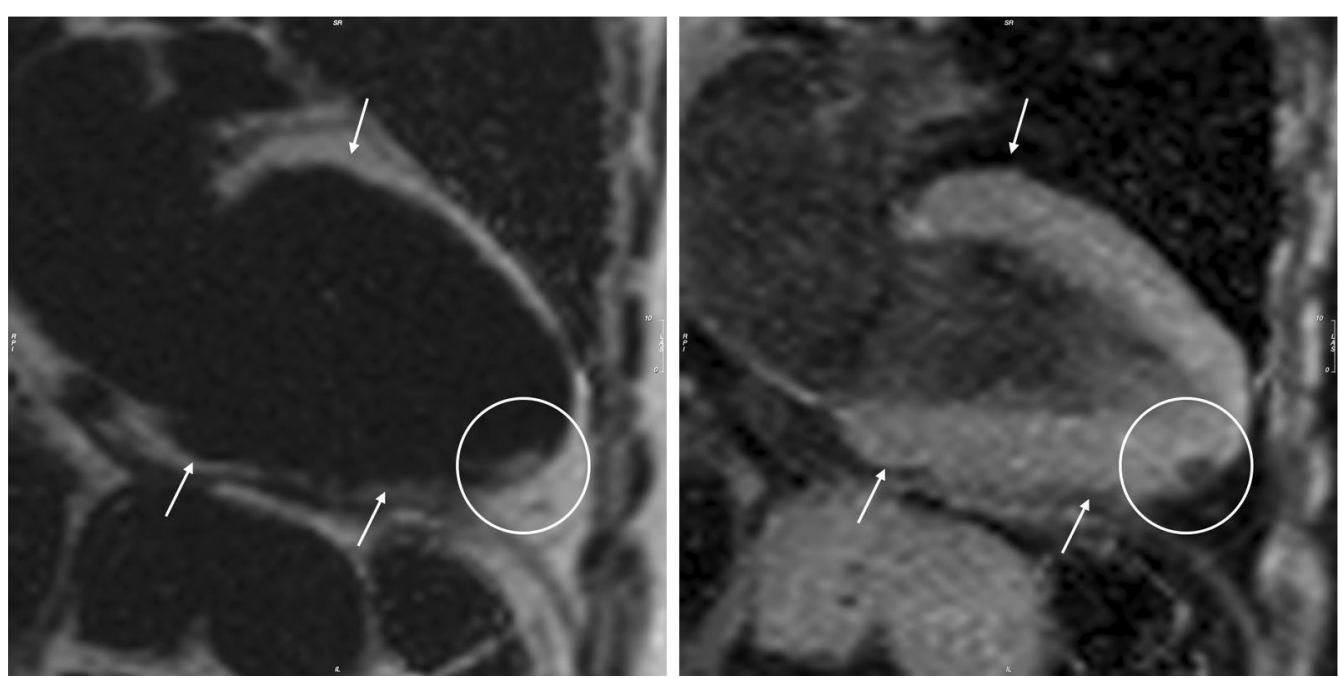

Fig. 7. 2-chamber view. Patient with FSHD1 and new intramyocardial apical fat infiltration- white circles. Bright in the fat-separated image (left) and hypointense (right) in the water-separated image. Epicardial fat - white arrows 
risk of SCD when compared to those with normal ECGs. In Emery Dreifuss MD cardiac involvement is predominantly identified by conduction defects and atrial fibrillation/flutter. These patients often show atrial dilation in different stages [32, 33].

Patients with MD2 and FSHD1 are known to suffer from supraventricular arrhythmias as well as conduction disturbances like AV blocks [11]. In our group we observed the progression of atrial enlargement and a decrease of atrial function. This may explain the progression of SVT. Recently published studies have shown that multiple atrial premature contractions and SVTs predict stroke recurrence in patients with cryptogenic stroke without atrial fibrillation and may be a reproducible marker of atrial myopathy [33, 34]. Interestingly, Winterholler et al. showed an increased risk for ischemic strokes in DMD patients. It is suspected that cardioembolic stroke is an under-recognized complication in patients with MD [34-36].

Parametric mapping is a method that brings unique quantitative diagnostic information concerning the myocardium.

In our cohorts we observed an increase of the number of focal myocardial changes as well as a worsening of GLS. T2 decreased significantly. T1 values stayed stable in most segments while ECV dropped significantly in both groups. The correlation of the EVC to the LVmorphology showed, that meanwhile the cell volume stayed constant, the volume of fibrosis was lower at follow-up. The cause for the decrease remains speculative (possible cardioprotective medication, progressive fat infiltration?). We have further discussed progressive fat infiltration as a possible explanation, as one could expect especially in this disease, further remodeling in this direction. However, we refused this possibility because $\mathrm{T} 2$ decreased. The explanation remains speculative, but an influence of anti-remodeling medications and myocardial deoxygenation could explain the observed mapping variations. We assume, that the decrease of $\mathrm{T} 2$ can be explained by $\mathrm{T} 2 *$ effects and may reflect a deterioration of myocardial oxygenation that may play a role in the further development of fibrosis. It was previously shown, that lower $\mathrm{T} 2$ * mapping values are related to alterations in the myocardial microcirculation. Manka et al. showed that BOLD CMR (blood oxygen level dependent) at rest revealed significantly lower $\mathrm{T}^{*}$ values for segments supplied by $>50 \%$ stenosed vessels [37]. Friedrich et al. presented the decrease of signal intensity during adenosine perfusion imaging within segments related to coronary artery stenoses $>75 \%$ [38]. Significant changes were also found in hypertensive patients compared to healthy controls [39].
We assume that the decrease of ECV at follow-up is probably related to a change of therapy between the two time points. The cardioprotective medication was optimized including ACE inhibitors. This may play a role in regards to the myocardial tissue changes within the whole group. Interestingly, Raman et al. could further show, that ACEI and mineralocorticoid receptor antagonists have an influence on fibrosis in MD [40]. There is no systematic CMR analysis investigating the effects of beta receptor blockade. This thesis is supported by our calculations, which show a reduced fibrosis volume with an unchanged total cell volume. Further follow-up trials will help to increase the understanding of these phenomenon's and to define its impact on the patient prognosis.

Quantification of myocardial deformation is of growing interest in CMR. Although relatively new, CMR feature tracking has been performed in various myocardial diseases like cardiomyopathies, aortic valve diseases or myocardial infarction. It allows quantification of global and regional myocardial deformation offering additional information beyond ejection fraction and has the potential to detect subclinical myocardial dysfunction in patients with non-ischemic heart disease even in preserved ejection fraction and without wall motion abnormalities [41, 42].

In our cohort, GLS was significantly lower at follow up although global LV function was preserved. That could also be shown in patients without focal myocardial injury. It seems that a volumetric approach using LVEF may be less reliable during the first years of follow-up regarding the early phase of subclinical LV remodeling.

In our study we observed a remarkably fast progressive decline of the cardiac morphology and function as well as a progression of rhythm disturbances including arrhythmias, even in asymptomatic patients (see Fig. 5). Both ventricles as well as atria were affected. The changes occurred within 2-5 years. This underlines the need for routine ECG or echocardiographic testing even in asymptomatic patients. Currently, routine ECG and/or echocardiographic exams are only indicated in symptomatic FSHD1 patients.

Further multi-center follow-up studies are needed to understand the relation between cardiac remodeling in $\mathrm{MD}$ and the outcome. However, regular use of CMR for follow-up in these patients may provide a valuable risk stratification tool in the future.

\section{Limitations}

Our sample size is relatively small, but both cohorts are recognized as rare diseases and this is the first follow-up study in this cohort. It was not possible to 
perform ECG-monitoring in all patients due to logistical reasons. This is an observational prospective cohort study, therefore there was no randomization into different treatment groups. Nevertheless, there is a potential impact of many other factors like progressive fat infiltration as well as the received therapy during the follow-up period, which should be taken into consideration. Currently, there are not enough data to report outcome analysis.

\section{Conclusions}

Patients with MDs gain an increasing awareness in cardiology. We observed a remarkably fast progressive decline of cardiac morphology and function as well as a progression of rhythm disturbances including arrhythmias, even in asymptomatic patients. These changes occurred within a short period of time. It seems that a potential association between an increase of arrhythmias and progression of myocardial tissue damage such as focal fibrosis and fat infiltration exists. Our data suggest that these patients should be carefully followed to identify early development of remodeling and potential risks for the development of furthers cardiac events even in the absence of symptoms.

Longitudinal multi-center trials with a larger sample size will help to define the impact of our findings as well as further demonstrate a correlation between myocardial injury and arrhythmias in regards to long-term prognosis and therapeutic decision-making.

\footnotetext{
Abbreviations

2Ch: Two chamber; 3Ch: Three chamber; 4Ch: Four chamber; ACE: Angiotensin converting enzyme; AHA: American Heart Association; ARB: Angiotensin receptor blocker; AV: Atrioventricular; BMD: Becker muscle dystrophy; bSSFP: Balanced steady state free precession; CMR: Cardiovascular magnetic resonance; DMD: Duchenne muscle dystrophy; ECG: Electrocardiogram; ECV: Extracellular volume fraction; FSHD1: Facioscapulohumeral muscular dystrophy type 1; GLS: Globla longitudinal strain; GRE: Gradient echo; LA: Left atrium/left atrial; LAEDV: Left atrial end-diastolic volume; LAEDVI: Left atrial end-diastolic volume index; LGE: Late gadolinium enhancement; LV: Left ventricle/left ventricular; LVEDV: Left ventricular end-diastolic volume; LVEDVI: Left ventricular end-diastolic volume index; LVEF: Left ventricular ejection fraction; MD: Muscular dystrophy; MD1: Myotonic dystrophy type 1; MD2: Myotonic dystrophy type 2; MOLLI: Modified Look-Locker inversion recovery; NSVT: Non-sustained ventricular tachycardia; PVC: Premature ventricular constrictions.; RA: Right atrium/right atrial; ROI: Region of interest; RV: Right ventricle/ right ventricular; RVEDV: Right ventricular end-diastolic volume; RVEDVI: Right ventricular end-diastolic volume index; RVEF: Right ventricular ejection fraction; SAx: Short axis; SCD: Sudden cardiac death; STRM: Signal threshold versus reference mean; SVT: Supraventricular tachycardia.
}

\section{Acknowledgements}

We acknowledge the technicians Kerstin Kretschel, Denise Kleindienst and Martina Kohla for assisting in acquiring the CMR data, the study nurses Elke Nickel and Annette Koehler for assisting with study logistics and Natalie Kaban for the help in language editing.

\section{Authors' contributions}

All authors participated in the discussion of the concept of the study. EB and JSM conceived the study design. EB and CL obtained CMR images and analyzed CMR scans. EB, CL, JG, PK, SS, LS and JSM analyzed the data. EB, JSM drafted the manuscript. As authors, we attest to each of our substantial contributions to the manuscript and critical revision. All authors read and approved the final manuscript.

\section{Funding}

Open Access funding enabled and organized by Projekt DEAL.

\section{Availability of data and materials}

The datasets used and/or analyzed during the current study are available from the corresponding author on reasonable request.

\section{Declarations}

Ethics approval and consent to participate

The study design was approved by the local ethics committee (The ethical board of the Charité University Medicine Berlin, EA1/042/17) and was conducted according to the Declaration of Helsinki. Written informed consent was obtained from all study participants.

\section{Consent for publication}

All authors approved the manuscript and are aware of the data.

\section{Competing interests}

$\mathrm{EB}, \mathrm{CL}, \mathrm{JG}, \mathrm{PK}, \mathrm{SS}, \mathrm{LS}$ and JSM declare that they have no competing interests.

\section{Author details}

${ }^{1}$ Department of Cardiology and Nephrology, Working Group Onn Cardiovascular Magnetic Resonance, Experimental and Clinical Research Center a Joint Cooperation Between the Charité - Universitätsmedizin Berlin, Department of Internal Medicine and Cardiology and the Max-Delbrueck Center for Molecular Medicine, and HELIOS Klinikum Berlin Buch, Lindenberger Weg 80, 13125 Berlin, Germany. ${ }^{2}$ DZHK (German Centre for Cardiovascular Research), Partner Site Berlin, Berlin, Germany. ${ }^{3}$ National Heart, Lung and Blood Institute, National Institute of Health, Bethesda, USA. ${ }^{4}$ Muscle Research Unit, Experimental and Clinical Research Center a Jointoint Cooperationoperation Betweenetween the Charité Medical, Berlin, Germany.

Received: 20 September 2020 Accepted: 10 September 2021

Published online: 08 November 2021

\section{References}

1. Baccouche H, Yilmaz A, Alscher D, Klingel K, Val-Bernal JF, Mahrholdt $\mathrm{H}$. Images in cardiovascular medicine. Magnetic resonance assessment and therapy monitoring of cardiac involvement in Churg-Strauss syndrome. Circulation. 2008;117:1745-9.

2. Hor KN, Taylor MD, Al-Khalidi HR, Cripe LH, Raman SV, Jefferies JL, O'Donnell R, Benson DW, Mazur W. Prevalence and distribution of late gadolinium enhancement in a large population of patients with Duchenne muscular dystrophy: effect of age and left ventricular systolic function. J Cardiovasc Magn Reson. 2013;15:107.

3. Menon SC, Etheridge SP, Liesemer KN, Williams RV, Bardsley T, Heywood MC, Puchalski MD. Predictive value of myocardial delayed enhancement in Duchenne muscular dystrophy. Pediatr Cardiol. 2014;35:1279-85

4. Finsterer J, Stollberger C. Cardiac involvement in primary myopathies. Cardiology. 2000;94:1-11.

5. Tonini MM, Passos-Bueno MR, Cerqueira A, Matioli SR, Pavanello R, Zatz M. Asymptomatic carriers and gender differences in facioscapulohumeral muscular dystrophy (FSHD). Neuromusc Disorders. 2004;14:33-8.

6. Suominen T, Bachinski LL, Auvinen S, Hackman P, Baggerly KA, Angelini C, Peltonen L, Krahe R, Udd B. Population frequency of myotonic dystrophy: higher than expected frequency of myotonic dystrophy type 2 (DM2) mutation in Finland. Eur J Human Genet. 2011;19:776-82. 
7. Day JW, Ricker K, Jacobsen JF, Rasmussen LJ, Dick KA, Kress W, Schneider C, Koch MC, Beilman GJ, Harrison AR, Dalton JC, Ranum LP. Myotonic dystrophy type 2: molecular, diagnostic and clinical spectrum. Neurology. 2003;60:657-64.

8. Tawil R, Padberg GW, Shaw DW, van der Maarel SM, Tapscott SJ and Participants FW. Clinical trial preparedness in facioscapulohumeral muscular dystrophy: Clinical, tissue, and imaging outcome measures 29-30 May 2015, Rochester, New York. Neuromuscular disorders: NMD. 2015.

9. Tawil R, Kissel JT, Heatwole C, Pandya S, Gronseth G, Benatar M, Guideline Development D, Implementation Subcommittee of the American Academy of N, Practice Issues Review Panel of the American Association of $\mathrm{N}$ and Electrodiagnostic M. Evidence-based guideline summary: Evaluation, diagnosis, and management of facioscapulohumeral muscular dystrophy: Report of the Guideline Development, Dissemination, and Implementation Subcommittee of the American Academy of Neurology and the Practice Issues Review Panel of the American Association of Neuromuscular \& Electrodiagnostic Medicine. Neurology. 2015;85:357-64.

10. Trevisan CP, Pastorello E, Armani M, Angelini C, Nante G, Tomelleri G, Tonin P, Mongini T, Palmucci L, Galluzzi G, Tupler RG, Barchitta A. Facioscapulohumeral muscular dystrophy and occurrence of heart arrhythmia. Eur Neurol. 2006;56:1-5.

11. Sansone VA, Brigonzi E, Schoser B, Villani S, Gaeta M, De Ambroggi G, Bandera F, De Ambroggi L, Meola G. The frequency and severity of cardiac involvement in myotonic dystrophy type 2 (DM2): long-term outcomes. Int J Cardiol. 2013;168:1147-53.

12. Schmacht L, Traber J, Grieben U, Utz W, Dieringer MA, Kellman P, Blaszczyk E, von Knobelsdorff-Brenkenhoff F, Spuler S, Schulz-Menger J. Cardiac involvement in myotonic dystrophy type 2 patients with preserved ejection fraction: detection by cardiovascular magnetic resonance. Circ Cardiovasc Imag. 2016;9:1.

13. Blaszczyk E, Grieben U, von Knobelsdorff-Brenkenhoff F, Kellman P, Schmacht L, Funk S, Spuler S, Schulz-Menger J. Subclinical myocardial injury in patients with Facioscapulohumeral muscular dystrophy 1 and preserved ejection fraction - assessment by cardiovascular magnetic resonance. J Cardiovasc Magn Reson. 2019;21:25.

14. Seferovic PM, Polovina M, Bauersachs J, Arad M, Gal TB, Lund LH, Felix $S B$, Arbustini E, Caforio ALP, Farmakis D, Filippatos GS, Gialafos E, Kanjuh V, Krljanac G, Limongelli G, Linhart A, Lyon AR, Maksimovic R, Milicic D, Milinkovic I, Noutsias M, Oto A, Oto O, Pavlovic SU, Piepoli MF, Ristic AD, Rosano GMC, Seggewiss H, Asanin M, Seferovic JP, Ruschitzka F, Celutkiene J, Jaarsma T, Mueller C, Moura B, Hill L, Volterrani M, Lopatin Y, Metra M, Backs J, Mullens W, Chioncel O, de Boer RA, Anker S, Rapezzi C, Coats AJS, Tschope C. Heart failure in cardiomyopathies: a position paper from the Heart Failure Association of the European Society of Cardiology. Eur J Heart Fail. 2019;21:553-76.

15. Seferovic PM, Polovina MM, Coats AJS. Heart failure in dilated non-ischaemic cardiomyopathy. Eur Heart J Suppl. 2019;21:M40-3.

16. Groh WJ, Groh MR, Saha C, Kincaid JC, Simmons Z, Ciafaloni E, Pourmand R, Otten RF, Bhakta D, Nair GV, Marashdeh MM, Zipes DP, Pascuzzi RM. Electrocardiographic abnormalities and sudden death in myotonic dystrophy type 1. N Engl J Med. 2008;358:2688-97.

17. Kellman P, Hernando D, Shah S, Zuehlsdorff S, Jerecic R, Mancini C, Liang ZP, Arai AE. Multiecho dixon fat and water separation method for detecting fibrofatty infiltration in the myocardium. Magn Reson Med. 2009:61:215-21.

18. von Knobelsdorff-Brenkenhoff F, Schuler J, Doganguzel S, Dieringer MA, Rudolph A, Greiser A, Kellman P, Schulz-Menger J. Detection and monitoring of acute myocarditis applying quantitative cardiovascular magnetic resonance. Circ Cardiovasc Imag. 2017;10:1

19. Schulz-Menger J, Bluemke DA, Bremerich J, Flamm SD, Fogel MA, Friedrich MG, Kim RJ, von Knobelsdorff-Brenkenhoff F, Kramer CM, Pennell DJ, Plein S, Nagel E. Standardized image interpretation and post-processing in cardiovascular magnetic resonance - 2020 update : Society for Cardiovascular Magnetic Resonance (SCMR): Board of Trustees Task Force on Standardized Post-Processing. J Cardiovasc Magn Reson. 2020;22:19.

20. Funk S, Kermer J, Doganguezel S, Schwenke C, von Knobelsdorff-Brenkenhoff F, Schulz-Menger J. Quantification of the left atrium applying cardiovascular magnetic resonance in clinical routine. Scand Cardiovasc J. 2018;52:85-92.

21. Muehlberg F, Arnhold K, Fritschi S, Funk S, Prothmann M, Kermer J, Zange $\mathrm{L}$, von Knobelsdorff-Brenkenhoff F, Schulz-Menger J. Comparison of fast multi-slice and standard segmented techniques for detection of late gadolinium enhancement in ischemic and non-ischemic cardiomyopathy - a prospective clinical cardiovascular magnetic resonance trial. J Cardiovasc Magn Reson. 2018;20:13

22. Mikami Y, Kolman L, Joncas SX, Stirrat J, Scholl D, Rajchl M, Lydell CP, Weeks SG, Howarth AG, White JA. Accuracy and reproducibility of semiautomated late gadolinium enhancement quantification techniques in patients with hypertrophic cardiomyopathy. J Cardiovasc Magn Reson. 2014;16:85.

23. Storz C, Hetterich $H$, Lorbeer $R$, Heber SD, Schafnitzel A, Patscheider $H$, Auweter S, Zitzelsberger T, Rathmann W, Nikolaou K, Reiser M, Schlett $\mathrm{CL}$, von Knobelsdorff-Brenkenhoff F, Peters A, Schulz-Menger J, Bamberg F. Myocardial tissue characterization by contrast-enhanced cardiac magnetic resonance imaging in subjects with prediabetes, diabetes, and normal controls with preserved ejection fraction from the general population. Eur Heart J Cardiovasc Imaging. 2018;19:701-8.

24. Cerqueira MD, Weissman NJ, Dilsizian V, Jacobs AK, Kaul S, Laskey WK, Pennell DJ, Rumberger JA, Ryan T, Verani MS, American Heart Association Writing Group on Myocardial S and Registration for Cardiac I. Standardized myocardial segmentation and nomenclature for tomographic imaging of the heart. A statement for healthcare professionals from the Cardiac Imaging Committee of the Council on Clinical Cardiology of the American Heart Association. Circulation. 2002;105:539-42.

25. Lim C, Blaszczyk E, Riazy L, Wiesemann S, Schuler J, von KnobelsdorffBrenkenhoff F and Schulz-Menger J. Quantification of myocardial strain assessed by cardiovascular magnetic resonance feature tracking in healthy subjects-influence of segmentation and analysis software. Eur Radiol. 2020.

26. Florian A, Ludwig A, Rosch S, Yildiz H, Sechtem U, Yilmaz A. Myocardial fibrosis imaging based on T1-mapping and extracellular volume fraction (ECV) measurement in muscular dystrophy patients: diagnostic value compared with conventional late gadolinium enhancement (LGE) imaging. Eur Heart J Cardiovasc Imaging. 2014;15:1004-12.

27. Florian A, Ludwig A, Engelen M, Waltenberger J, Rosch S, Sechtem U, Yilmaz A. Left ventricular systolic function and the pattern of lategadolinium-enhancement independently and additively predict adverse cardiac events in muscular dystrophy patients. J Cardiovasc Magn Reson. 2014;16:81.

28. Hasselberg NE, Haland TF, Saberniak J, Brekke PH, Berge KE, Leren TP, Edvardsen T, Haugaa KH. Lamin A/C cardiomyopathy: young onset, high penetrance, and frequent need for heart transplantation. Eur Heart J. 2018:39:853-60.

29. Florian A, Rosch S, Bietenbeck M, Engelen M, Stypmann J, Waltenberger J, Sechtem U, Yilmaz A. Cardiac involvement in female Duchenne and Becker muscular dystrophy carriers in comparison to their first-degree male relatives: a comparative cardiovascular magnetic resonance study. Eur Heart J Cardiovasc Imaging. 2016;17:326-33.

30. Lu M, Zhao S, Jiang S, Yin G, Wang C, Zhang Y, Liu Q, Cheng H, Ma N, Zhao T, Chen X, Huang J, Zou Y, Song L, He Z, An J, Renate J, Xue H, Shah S. Fat deposition in dilated cardiomyopathy assessed by CMR. JACC CardiovasC Imaging. 2013;6:889-98.

31. Finsterer J, Stollberger C. Heart disease in disorders of muscle, neuromuscular transmission, and the nerves. Kor Circ J. 2016:46:117-34.

32. Ismail H, Raynor E, Zimetbaum P. Neuromuscular disorders and the role of the clinical electrophysiologist. JACC Clin Electrophysiol. 2017;3:1069-79.

33. Boriani G, Gallina M, Merlini L, Bonne G, Toniolo D, Amati S, Biffi M, Martignani C, Frabetti L, Bonvicini M, Rapezzi C, Branzi A. Clinical relevance of atrial fibrillation/flutter, stroke, pacemaker implant, and heart failure in Emery-Dreifuss muscular dystrophy: a long-term longitudinal study. Stroke. 2003;34:901-8.

34. Cha J-J, Chung H, Uhm J-S, Joung B, Pak H-N, Lee M-H, Kim J-Y. Multiple atrial premature contractions predict stroke recurrence in patients with cryptogenic stroke and concomitant non-sustained atrial tachycardia. Int J Arrhythmia. 2020;21:5.

35. Chen CH, Tang SC, Su YN, Yang CC, Jeng JS. Cardioembolic stroke related to limb-girdle muscular dystrophy 1B. BMC Res Notes. 2013;6:32.

36. Winterholler M, Hollander C, Kerling F, Weber I, Dittrich S, Turk M and Schroder R. Stroke in Duchenne Muscular Dystrophy: A Retrospective Longitudinal Study in 54 Patients. Stroke. 2016. 
37. Manka R, Paetsch I, Schnackenburg B, Gebker R, Fleck E, Jahnke C. BOLD cardiovascular magnetic resonance at 30 tesla in myocardial ischemia. J Cardiovasc Magn Reson. 2010;12:54.

38. Friedrich MG, Karamitsos TD. Oxygenation-sensitive cardiovascular magnetic resonance. J Cardiovasc Magn Reson. 2013;15:43.

39. Bernhardt P, Manzke R, Bornstedt A, Gradinger R, Spiess J, Walcher D, Rasche V, Hombach V. Blood oxygen level-dependent magnetic resonance imaging using T2-prepared steady-state free-precession imaging in comparison to contrast-enhanced myocardial perfusion imaging. Int J Cardiol. 2011;147:416-9.

40. Raman SV, Hor KN, Mazur W, Halnon NJ, Kissel JT, He X, Tran T, Smart S, McCarthy B, Taylor MD, Jefferies JL, Rafael-Fortney JA, Lowe J, Roble SL, Cripe LH. Eplerenone for early cardiomyopathy in Duchenne muscular dystrophy: a randomised, double-blind, placebo-controlled trial. Lancet Neurol. 2015;14:153-61.
41. Neisius U, Myerson L, Fahmy AS, Nakamori S, El-Rewaidy H, Joshi G, Duan C, Manning WJ, Nezafat R. Cardiovascular magnetic resonance feature tracking strain analysis for discrimination between hypertensive heart disease and hypertrophic cardiomyopathy. PLoS ONE. 2019;14:e0221061.

42. Vigneault DM, Yang E, Jensen PJ, Tee MW, Farhad H, Chu L, Noble JA, Day SM, Colan SD, Russell MW, Towbin J, Sherrid MV, Canter CE, Shi L, Ho CY, Bluemke DA. Left ventricular strain is abnormal in preclinical and overt hypertrophic cardiomyopathy: cardiac mr feature tracking. Radiology. 2019;290:640-8.

\section{Publisher's Note}

Springer Nature remains neutral with regard to jurisdictional claims in published maps and institutional affiliations.
Ready to submit your research? Choose BMC and benefit from:

- fast, convenient online submission

- thorough peer review by experienced researchers in your field

- rapid publication on acceptance

- support for research data, including large and complex data types

- gold Open Access which fosters wider collaboration and increased citations

- maximum visibility for your research: over $100 \mathrm{M}$ website views per year

At BMC, research is always in progress.

Learn more biomedcentral.com/submissions 